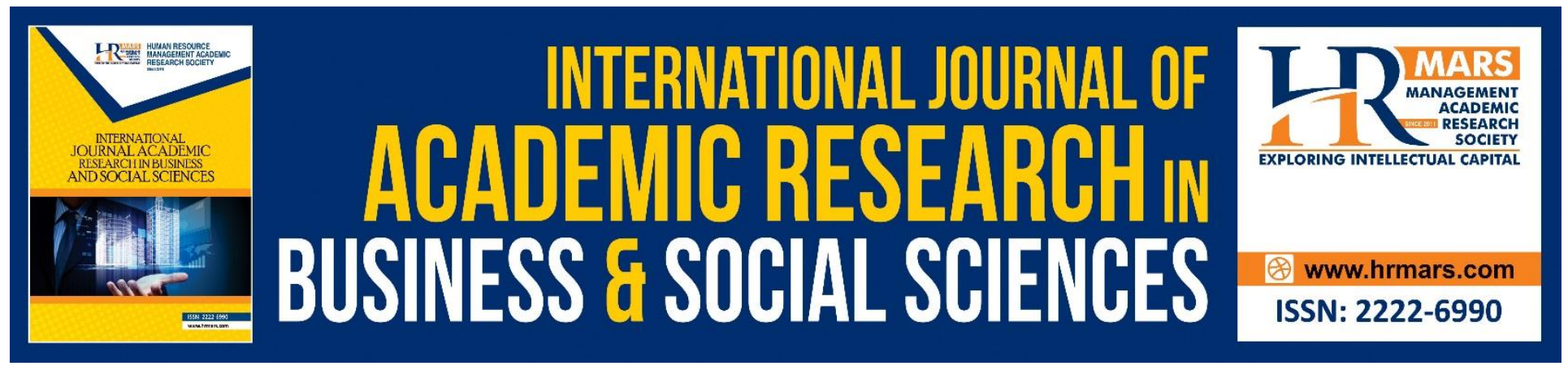

\title{
Strategic Audit of Human Resource Management and its Effect on the Efficiency of Employees in the Jordanian Customs Department
}

Layla Turki Alnadi

To Link this Article: http://dx.doi.org/10.6007/IJARBSS/v9-i3/5751

DOI: $\quad 10.6007 /$ IJARBSS/v9-i3/5751

Received: 06 Jan 2019, Revised: 17 March 2019, Accepted: 30 March 2019

Published Online: 10 April 2019

In-Text Citation: (Alnadi, 2019)

To Cite this Article: Alnadi, L. T. (2019). Strategic Audit of Human Resource Management and its Effect on the Efficiency of Employees in the Jordanian Customs Department. International Journal of Academic Research in Business and Social Sciences, 9(3), 860-874.

Copyright: (C) 2019 The Author(s)

Published by Human Resource Management Academic Research Society (www.hrmars.com)

This article is published under the Creative Commons Attribution (CC BY 4.0) license. Anyone may reproduce, distribute, translate and create derivative works of this article (for both commercial and non-commercial purposes), subject to full attribution to the original publication and authors. The full terms of this license may be seen at: http://creativecommons.org/licences/by/4.0/legalcode

Vol. 9, No. 3, 2019, Pg. 860 - 874

http://hrmars.com/index.php/pages/detail/IJARBSS

JOURNAL HOMEPAGE

Full Terms \& Conditions of access and use can be found at http://hrmars.com/index.php/pages/detail/publication-ethics 


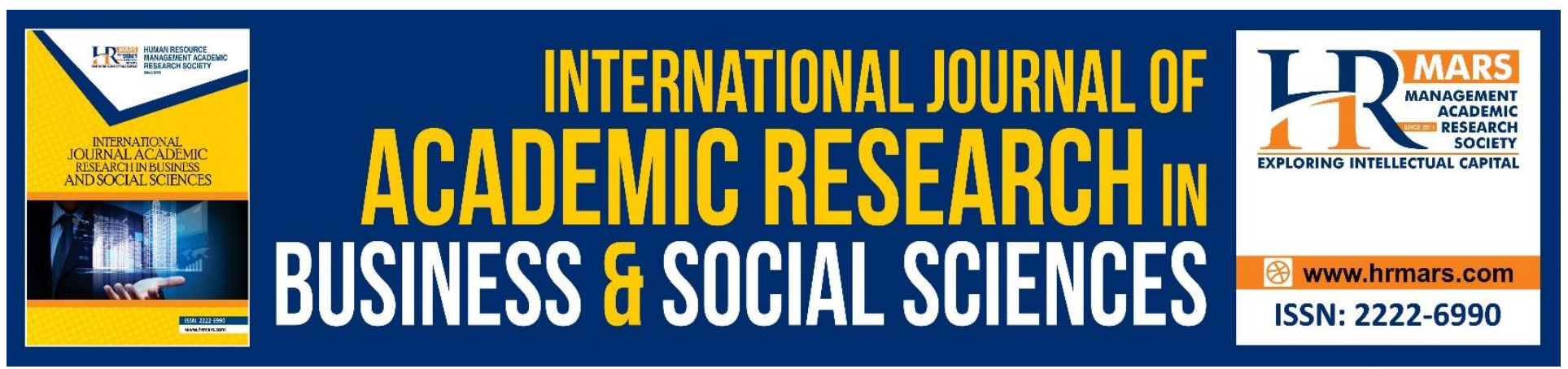

\title{
Strategic Audit of Human Resource Management and its Effect on the Efficiency of Employees in the Jordanian Customs Department
}

\author{
Layla Turki Alnadi \\ Ministry of Health \\ Email: Laila.alnadi@yahoo.com
}

\begin{abstract}
This study aimed to identify the impact of strategic auditing on human resources management in the efficiency of employees in the Jordanian Customs Department. To achieve this, the researchers distributed a questionnaire that consisting of (30) paragraphs distributed over five dimensions. The community of study consists of all employees in the department at the upper, middle and lower management levels in the Jordan Customs Department and their number are 500employees, The study concluded that there is a statistically significant impact on the dimensions of the strategic audit of human resources management in general (personnel auditing and policy auditing) in the Jordanian Customs Department.
\end{abstract}

Keywords: Strategic Audit of Human Resource Management, Employee Efficiency, Customs, Jordan

\section{Introduction}

The strategic audit of human resources management is one of the latest in the field of human resources management. It emphasizes the vital role of human capital and thus achieves its strategic objectives. It helps to apply the concept of human resource management audit in organizations to the optimal utilization of human capital, It is one of the most important methods of diagnosing the problems and obstacles that faced organizations in the implementation of their strategic plans. It includes a detailed analysis of the performance of all aspects of the various functions and activities of the organization and the level of performance of its current strategic plans (Bogardus, 2014) the strategic audit is consider the process of professional examination of books, records and documents of the Organization, neutral and critical examination to validate processes and to express an opinion in the fairness of the financial statements of the Organization depending on the strength of the internal control system (Helmy, 2009).

The idea of strategic auditing was quoted from accounting science and accounting auditing to be used to examine and evaluate the organization's operational processes that affect the strategic 
management process, decisions and plans and strategies. Strategic auditing is considered a diagnostic process through which know deviations If any, and make decisions thereon (Masadeh, 2013). According to( Thabet and Al Habib ,2009) (obeidat et al.,2018), that investment in human resources is the real investment, and (Akhwirshidah,2006) points out that it is the basis for every economic process, which supports the strategic objectives of any department. The department therefore seeks to balance the needs and desires of its employees by finding suitable means To make the work more able to satiate those needs, to reflect on raising the rates of their performance at work.

The efficiency of the human resource isa key to excellence of the department, and Human resources management is responsible for building the efficiency required to achieve sustainable value and converting this efficiency into practices that contribute to achieving better performance and make the department more competitive by planning, organizing, directing and controlling the efficiency of human resources in the department by applying the strategic audit and the strategic controlling which enhance the competitive position of the department and its excellence in the implementation of plans to achieve its strategic objectives(Habib and Jilali,2009). The strategic value of the organization lies in the value of its human resources and its competencies such as the capital of the

jaw $\mathrm{RI}$, and the ability of this organization to employ the knowledge inherent in it and turn it into applications that achieve outstanding performance and thus improve their competitiveness (Harem, 2013) (Obeidat \& Otibi, 2015).

\section{Theoretical Framework Strategic Audit}

The American Accounting Association (AAA) has defined auditing as a systematic and objective process to obtain and evaluate evidence of facts about economic events and events to ascertain the degree of conformity between those facts and the specific criteria and to reach the results to users of information who interested in verification. (Helmi ,2009) identified the audit from the professional point of view: it's the examination process of the books, records and documents of the organization a neutral critical examination, to verify the validity of operations and to express an opinion on the fairness of the financial statements of the organization depending on the strength of the internal control system. A strategic audit of human resources is the process of reviewing the organization by supreme management of all activities which practiced by the management of human resources and work on analyzing them in order to correct deviations and make the necessary decision thereon (Bareqawi, 2013). Strategic audit can be defined by the vision of (Al Salem, 2009) and through the strategic management data that Review process organized by the senior management of all human resources management activities: functions, policies, procedures and practices, and analysis in order to find out and correct deviations and make the necessary decisions.

and strategic audit gains it is important from the changes for the eternal and external factors, These factors and variables are not fixed in the long term, therefore it affect the strengths, weaknesses, the opportunities and risks of the institutions. These changes will include the timing, method or manner in which they will be carried out (Al-Douri, 2005). The important deviations in the strategic audit represented in audit of individuals, audit costs, audit functions, audit policies, and audit human resources activities. Therefore, researchers may consider only two dimensions - audit of individual 
INTERNATIONAL JOURNAL OF ACADEMIC RESEARCH IN BUSINESS AND SOCIAL SCIENCES

Vol. 9, No. 3, March, 2019, E-ISSN: 222 2-6990 ㄷ 2019 HRMARS

and audit of policy - because they are more relevant and relevant to the current study (Momani, 2015). The details of these dimensions can be described as follows:

\section{Audit of Individuals}

It includes the audit of human resources working in the institution quality and quantity. It includes skills and abilities possessed by human forces; it includes level of individual, collective and motivation performance of the work, trends and values prevailing among these forces. This field includes knowledge of the efficiency and effectiveness in exploiting and using the skills and abilities existing between (Momani, 2015). The audit team reviews and edit the following aspects:

- Checking skills to know the gap between the skills and abilities available in the department, and the extent of the need of the institution for some skills. Based on these results, the training needs of working individuals are identified in order to acquire new skills that help to achieve the objectives of the department (Mackey, 2006).

- Determining the criteria for evaluating the actual performance and the required performance for the employees in the department, measuring the level of performance required to be compared and comparing it with the actual performance of the employees. The importance of auditing of the performance of the employees stems from the official outcome of the achievement of individuals for the tasks that assigned to them and thus determining the weaknesses and strength in performing these tasks and the effectiveness of the individual to achieve the objectives of the Department (Debrincat, 2014).

\section{Policy Audit}

The human element is one of the most important elements that achieve the objectives and objectives of the department. Its importance lies in its direct and influential role in improving the quality of operations, increasing the level of performance, and achieving excellence and creativity inside and outside the organization (Aswathappa, 2005). This can be achieved through good planning of polarization, testing and recruitment of skilled and efficient individual and work on developing them in order to raise the level of performance and productivity, which requires a system of fair wages and compensation to be an incentive for individuals to remain in the department, and the public policy of human resources have to govern such activities and sub-policies that covering all the activities of that resources, and that each such policy is an executive and educational measures and how to achieve it(Kravcakova, 2013).

These policies and activities are reviewed and verified by ensuring that HRM works to formulate policies that govern the work, activities and practices of $H R$ in the department and to ensure that these policies are aligned with each other and with the overall strategy of the department and to understand employees' understanding and application of these policies (Pickett, 2010), in addition to audit of human resources management functions that would make human resources strategies at the center of implementation and focus on improving performance, enhancing human resource competencies, skills and knowledge in order to achieve strategic objectives (John, 2007). 


\section{Efficiency of Employees}

The concept of human competencies takes an important place at all levels inside the organization, from individual to collective, and finally at the department level as a whole. It is a set of incentives, attributes and skills that represent the self-image aspects of an individual's social role and serve as an appropriate knowledge of the characteristics and characteristics which is needed by the working individual (Harem, 2007), (Nordine ,2008)( Irtaimeh et al, 2016) identified as the system that can reduce the cost of resources to achieve the desired goals without sacrificing system outputs. (Robbins et al. (2012) ensures that efficiency means achieving as much as possible Of outputs with as little input as possible.

Continuing development and excellence Despite the strong competition that witnessed by the world through the direction of the knowledge economy, (Al-Shaikhi and Al-Qubaisi,2011) believes that the importance of competencies lies in building a permanent learning institution and adopting an open system through which the best ways to extract new ideas in addition to provide the management of the institution with a clear vision of the capabilities of its employees and attention to the knowledge held by the workers and cannot express. (Asia ,2010) sees that the aim of the competencies is to achieve the following benefits for the department and for individuals: to focus on the culture and values of the department, and to introduce the strategy of the department At the department level as a whole, focusing on improving employee performance, and providing a practical framework for the integration of HR applications.

Competencies and knowledge are a major challenge in the economic field and in the global community. They represent a fundamental pillar of organizational and societal development (Habib and Jilali, 2009). Competencies are also important mechanisms that enable the institution to achieve sustainable competitive advantage. It has many dimensions dealt with in the previous literature. Therefore, three dimensions have been chosen: practical efficiency, functional efficiency and structural efficiency.

Practical Efficiency: the practical efficiency means the efficiency associated with the job itself in terms of knowledge of the responsibilities and tasks that must be performed by the employee, and possess the suitable skills to perform work and make decisions on the best ways to accomplish the tasks or work entrusted to it, and know the type of technology used in production or performance and assign tasks that cannot be done Efficiently and efficiently by machines to individuals while at the same time accomplishing works that machines can accomplish faster and with higher quality than individuals can achieve (Hamley, 2011).

Functional Efficiency: It is the efficiency of the employees in the performance of their functions through the set of skills and experience that they possess, and are related to the relationship and the rest of the unit in terms of behavior and communication and organizational behavior. It is linked to the ability of individuals to employ them in the organizational position in the best way, and work as work team among Organizational units in order to achieve common goals while maintaining positive links at all levels and respect point of views. (Al-Ansari, 2010). (Hamdi, 2014) believes that functional competencies have many characteristics that give them a fixed value, that represent that they are of the same purpose and their formulation is done dynamically, and it is simple and acquired, In order 
to reach the functional efficiency to the outstanding performance, there must be several rules in the development of mechanisms of systemic thinking, and the commitment of scientific and methodological method to solve problems and decision-making, and the integration of the institution in the surrounding environment, and develop a sense of social responsibility in individuals Employees, recruitment and development of knowledge and renewal of employees, and provide a successful management leadership.

Structural Efficiency: it is efficiency that related to the method and procedures used in the performance of work, and the outcome of the knowledge, skills, procedures and trends that the employee is supposed to have and can practice in order to perform his functions and to define the structural efficiency, must know the organizational structure of the institution, that defines how must distribute tasks And what are the coordination mechanisms and patterns of interactions that should be followed. Organizational structure includes the following main areas: complexity, official, central (Al-Salem, 2009).

\section{Strategic Audit of Human Resources Management and its Impact on the Efficiency of Employees}

The audit of human resources management focuses on the human resource management functions of the organization, including the collection and analysis of data in a specific period, and the collection and analysis of data and information in the human resources audit process are directly related to the individuals, organizational structures, culture and philosophy of the institution. Human process usually covers Human resources management, and also focuses on human resource information system, human resource research system, archived files, return on investment in human resources, policies, procedures and functional alignment (Mirza S. Saiyadain 2009).

The strategic audit of human resource management works to develop human efficiency by avoiding mistakes, correcting wrong practices and taking advantage of the correct practices that facing the institution and human resources. This has a great impact on the efficiency of the human resource and the achievement of the objectives of the institution(Imam and Ali 2013)..

The practical competency is related to the job itself in terms of understanding the responsibilities and tasks through understanding the work instructions and then the ability to predict and organize the work, and respect the rules and instructions, as well as possess necessary skills to perform the work, as own the efficiency of implementation and good knowledge of work and ability to lead and work as team spirit and individual ability In the maintenance of tools work. The strategic audit works to check the practical efficiency of individuals through knowledge of deviations and problems that occur as a result of the lack of knowledge of the individual functions of the function entrusted to him and the knowledge of responsibilities and tasks and have the necessary skills to perform the work skills, monitor, and address the imbalance and take the necessary decision on them, and then make recommendations in order to live up to the highest degree of process efficiency (Masadeh, 2013).

Functional competence is the ability of employees to perform their functions by possessing a range of skills, experiences, behaviors and organizational behavior that can be employed in the organizational position, working in a team spirit to achieve common goals, possessing the knowledge and cognitive knowledge that lies within it, And the Department can possess these individuals to achieve outstanding performance and enhance their productive and service when this knowledge 
owned by individuals related to the nature of the work of the Department, and the role of strategic audit comes by detect of such as this competencies by audit the level of individual, collective and motivation performance of work and identifying the extent to which the skills and abilities available are used among the individuals, measuring the level of performance required and comparing them with the actual performance of the department, determining the gap between skills and abilities and identifying the training needs of individuals. Entrusted to them and the efficiency of individuals in achieving the objectives of the Department (Imam and Ali 2013).

Structural competence is related to the method and procedures, as it is the result of the knowledge, skills and behaviors that the employee has to perform the functions. However, good knowledge of the way the work is performed to eliminate of duplication and repetition, distribute tasks and defines responsibilities, and knows the legislative and regulatory rules and procedures to guide behavior and the degree of authority to take The decision in different administrative levels, the role of the strategic audit is coming to ensure the policies of audit of training and development policies, which provides the individual with the information and knowledge that gained by the skill in the performance of work and development of the Skills and knowledge and improve their abilities by methods and procedures used. The strategic audit process identifies individuals who need training or increase knowledge, make recommendations on them and work to improve the quality of their customs performance (Masadeh, 2013).

Theoretical Framework and Hypotheses Development Research Model Independent variable

The dependent variable

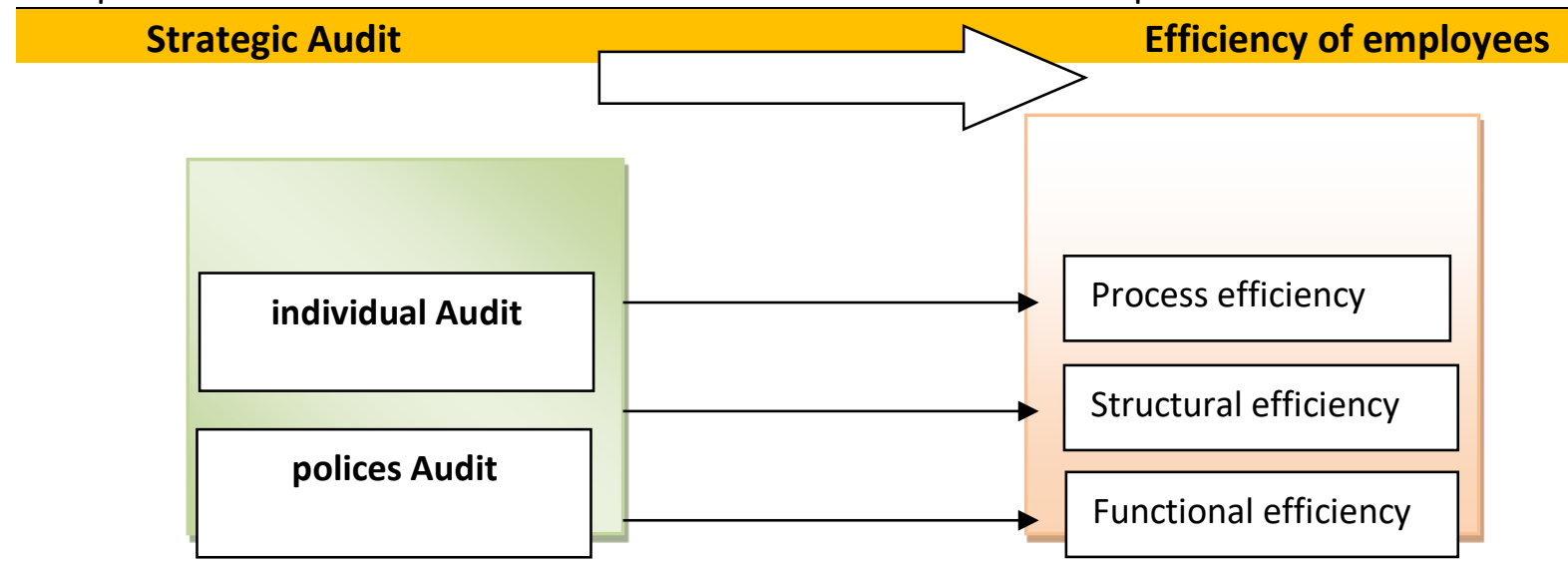

Figure (1) the researchers developed and developed this model based on previous studies (

Momani, 2015, Ben Jeddu , 2013)

\section{Research Hypotheses}

H1: There is a statistically significant impact of Strategic Audit on Efficiency of employees.

H1.1: There is a statistically significant impact of Strategic Audit on Process efficiency

H1.2: There is a statistically significant impact of Strategic Audit on Structural efficiency

H1.3: There is a statistically significant impact of Strategic Audit on Functional efficiency 


\section{Methodology}

\section{Survey}

To achieve the objectives of the study, questionnaires were developed that based on literature in the field of management. The study (Momani, 2015) was used to determine the dimensions and questions of the independent variable (strategic auditing, policy auditing and personnel auditing). As for the dependent variable ( Efficiency of workers and the development of practical efficiency And structural efficiency and functional efficiency), the study of (Ben Jeddou ,2013) and (Abu Al-jadeel ,2012) were adopted. Likert scale of five dimensional was adopted. Each of the paragraphs in the questionnaire was given five grades of approval (5-1) respectively, Where the number (5) corresponds to a very high degree, the number (4) correspond to high degree, the number (3) correspond with middle degree, (2) I agree with a low score, and (1) I agree very low. As for the limits that were adopted by this study to judge the arithmetic average to response The researcher on the paragraphs that related with the variable of the study that has identified three levels (high, medium, low), and to verify the validity of the study tool has been subjected to honesty of the test, which was presented to a group of arbitrators with experience and competence in the subject of the study, The researchers modified the tool of study in the opinion of the arbitrators and their observations deleted, or add to become more compatible with it goals, In order to enable accurate measurement of the variables of the study and its various dimensions until they finally emerged. As for the stability of the measuring instrument, the Cronbach alpha coefficient was extracted for the internal consistency of all measurements. As shown in Table (1), the values of stability coefficients (Kronbach alpha) for dimensions and fields ranged between 0.86-0.94 Are suitable and acceptable for application purposes as well. Most studies indicate that the stability factor acceptance ratio is 0.70 (Najjar and Zubi, 2013).

Table (1) Coherence Coefficient (Cronbach Alpha) of the study instrument.

\begin{tabular}{|l|l|l|}
\hline $\begin{array}{l}\text { Cronbach } \\
\text { Alpha }\end{array}$ & The dimension & The field \\
\hline 0.86 & Individual Audit & \multirow{2}{*}{ Strategic Audit } \\
\hline 0.90 & Polices Audit & \\
\hline 0.93 & Strategic Audit & \multirow{2}{*}{$\begin{array}{l}\text { Efficiency } \\
\text { employees }\end{array}$} \\
\hline 0.88 & Structural efficiency & \\
\hline 0.91 & Process efficiency & \\
\hline 0.89 & Functional efficiency & \\
\hline 0.94 & Efficiency employees & \\
\hline
\end{tabular}

\section{Study Sample}

The researchers used a simple random sample so that the study community of all workers in the three administrative levels in the customs department in Amman governorate (500) employees. The size of the withdrawn sample was determined on the size of the total population of (217) employees and the margin of error allowed in this The study is $(0,05)$ according to the scale of sample size required (Uma Sekaran, 2003) 
INTERNATIONAL JOURNAL OF ACADEMIC RESEARCH IN BUSINESS AND SOCIAL SCIENCES

Vol. 9, No. 3, March, 2019, E-ISSN: $2222-6990$ C 2019 HRMARS

\section{Result}

\section{Answer the Study Questions}

What is the level of implementation of the strategic audit of human resources management in the Jordanian Customs Department?

To answer this question, Mean and standard deviations were extracted for the level of implementation of the strategic audit of human resource management in the Jordanian Customs Department. These Mean and standard deviations were as follows in Table (2).

Table 2: mean and standard deviation of Strategic Audit

\begin{tabular}{|l|l|l|l|l|l|}
\hline Order & $\#$ & Variables & Mean & SD & level \\
\hline 1 & 1 & individual Audit & 3.98 & .672 & High \\
\hline 2 & 2 & polices Audit & 3.98 & .721 & High \\
\hline & & Strategic Audit & 3.98 & .662 & High \\
\hline
\end{tabular}

What is the level of competency required by the employees of the Jordanian Customs Department? To answer this question, the Mean and standard deviations were extracted for the level of competency availability required by the employees of the Jordanian Customs Department. The table below shows this.

Table 3: mean and standard deviation of Employee Efficiency

\begin{tabular}{|l|l|l|l|l|l|}
\hline Order & $\#$ & Variables & Mean & SD & level \\
\hline 1 & 1 & Process efficiency & 4.04 & .665 & High \\
\hline 2 & 2 & Structural efficiency & 4.00 & .679 & High \\
\hline 3 & 3 & Functional efficiency & 3.88 & .738 & High \\
\hline & & Employee Efficiency & 3.97 & .629 & High \\
\hline
\end{tabular}

\section{Testing Hypotheses}

H1: There is a statistically significant impact of Strategic Audit on Efficiency of employees

Table 4 The results of testing the hypothesis

\begin{tabular}{|l|l|l|l|l|l|l|l|}
\hline $\begin{array}{l}\text { Independent } \\
\text { variable }\end{array}$ & Beta & $\mathbf{t}$ & Sig t & $\mathbf{R}$ & $\mathbf{R}^{\mathbf{2}}$ & $\mathbf{F}$ & Sig F \\
\cline { 1 - 5 } $\begin{array}{l}\text { individual } \\
\text { Audit }\end{array}$ & .246 & 3.639 & .000 & .811 & .658 & 206.715 & .000 \\
\cline { 1 - 6 } polices & .599 & 8.858 & .000 & & & \\
\hline
\end{tabular}

The dependent variable Efficiency of employees 
Table (4) shows that there is a statistically significant effect at the level of significance (00.05 $\alpha$ ) for the strategic audit of human resources in the efficiency of the employees in the Jordanian Customs Department where the coefficient of correlation is $R(0.811)$. The coefficient of variance explained in R2 is (0.658) The dimensions of the strategic audit of human resources combined (Personnel Audit, Policy Auditing) (as an independent variable) accounted for $65.8 \%$ of the variation in the efficiency of employees in the Jordanian Customs Department (as a dependent variable). The rest (34.2\%) means that there are other independent variables Not included in the study model or may revert to random error affect the efficiency of employees of workers in the Jordanian Customs Department of individual's sample. The results of the survey showed that there was a positive effect on the efficiency of employees in terms of employee efficiency, which reached 3.639 and statistically significant 0.000 . there is a significant impact of auditing policies in the efficiency of employees 8.858 and statistically significant 0.000 . this results indicates to refuse The null hypothesis and the acceptance of the alternative hypothesis and its text "there is a significant statistical effect at the level of significance $(00.05 \alpha)$ for the strategic audit of human resources in the efficiency of workers in the Jordanian Customs Department."

H1.1: There is a statistically significant impact of Strategic Audit on Process efficiency

Table 5 The results of testing the hypothesis

\begin{tabular}{|l|l|l|l|l|l|l|l|}
\hline $\begin{array}{l}\text { Independent } \\
\text { variable }\end{array}$ & Beta & $\mathbf{t}$ & Sig t & $\mathbf{R}$ & $\mathbf{R}^{\mathbf{2}}$ & $\mathbf{F}$ & Sig F \\
\hline $\begin{array}{l}\text { individual } \\
\text { Audit }\end{array}$ & -.041 & -.520 & .604 & .729 & .532 & 122.156 & .000 \\
\cline { 1 - 6 } polices & .762 & 9.632 & .000 & & & & \\
\hline
\end{tabular}

The dependent variable Process efficiency

Table (5) shows that there is a statistically significant effect at the level of significance (00.05 $\alpha$ ) for the strategic audit of human resources in achieving practical efficiency at the Jordanian Customs Department where the coefficient of correlation is (0.729). The defined coefficient of interpretation was R2 (53.2\%) this means that the strategic audit of human resources combined (individual audit, policy audit) as dependent variable interpreted (53.2\%) of the variation in the practical efficiency of the Jordanian Customs Department (as a dependent variable), while the rest $(46.8 \%)$ means that there are other independent variables Not included in the study model or may be due to random error affect the achievement of the efficiency of the process in the Jordanian Customs Department for the sample members. It was also found that there was no statistically significant effect of the auditing of individuals on achieving the practical efficiency, which reached 0.520 and statistically 0.604 (indicating an inverse relationship between the dependent variable and the independent variable) A positive effect of the policy audits on achieving practical efficiency with a value of 9.632 in statistical terms 0.000 .

H1.2: There is a statistically significant impact of Strategic Audit on Structural efficiency

Table 6 The results of testing the hypothesis 
INTERNATIONAL JOURNAL OF ACADEMIC RESEARCH IN BUSINESS AND SOCIAL SCIENCES Vol. 9, No. 3, March, 2019, E-ISSN: 222 2-6990 @ 2019 HRMARS

\begin{tabular}{|l|l|l|l|l|l|l|l|}
\hline $\begin{array}{l}\text { Independent } \\
\text { variable }\end{array}$ & Beta & $\mathbf{t}$ & Sig t & $\mathbf{R}$ & $\mathbf{R}^{\mathbf{2}}$ & $\mathbf{F}$ & Sig F \\
\hline $\begin{array}{l}\text { individual } \\
\text { Audit }\end{array}$ & .350 & 4.497 & .000 & .739 & .546 & 129.383 & .000 \\
\cline { 1 - 6 } polices & .427 & 5.476 & .000 & & & & \\
\hline
\end{tabular}

The dependent variable Structural efficiency

Table (6) shows that there is a statistically significant effect at the level of significance $(00.05 \alpha)$ for the strategic audit of human resources in achieving the structural efficiency in the Jordanian Customs Department where the correlation coefficient is $R(0.739)$. The coefficient of variance explained in $R 2$ is (0.546) The dimensions of the strategic audit of human resources combined (Personnel Audit, Policy Auditing) (as an independent variable) accounted for $54.6 \%$ of the variation in achieving structural efficiency in the Jordanian Customs Department (as a dependent variable). The rest (45.4\%) means that there are other independent variables Not included in the study model or may revert to random error affect the realization of the efficiency of the structure in the Jordanian Customs Department for the sample members. It was also found that there was a positive effect on the auditing of individuals on the achievement of structural efficiency, with a value of 4.497 and with statistical significance of 0.00 , and a positive effect of the policy audit on achieving structural efficiency with a value of 5,476. And with statistical significant 000 .

H1.3: There is a statistically significant impact of Strategic Audit on Functional efficiency Table 7 The results of testing the hypothesis

\begin{tabular}{|l|l|l|l|l|l|l|l|}
\hline $\begin{array}{l}\text { Independent } \\
\text { variable }\end{array}$ & Beta & $\mathbf{t}$ & Sig t & $\mathbf{R}$ & $\mathbf{R}^{2}$ & $\mathbf{F}$ & Sig F \\
\cline { 1 - 5 } $\begin{array}{l}\text { individual } \\
\text { Audit }\end{array}$ & .344 & 4.548 & .000 & .757 & .573 & 144.234 & .000 \\
\cline { 1 - 6 } polices & .452 & 5.977 & .000 & & & \\
\hline
\end{tabular}

The dependent variable Functional efficiency

Table (7) shows that there is a statistically significant effect at the level of significance of $00.05(\alpha)$ for the strategic audit of human resources in achieving the functional efficiency in the Jordanian Customs Department where the correlation coefficient reaches $R(0.757)$. The coefficient of the explained variance was reached R2 (0.573) The dimensions of the strategic audit of human resources combined (Personnel Audit, Policy Audit) (as an independent variable) explained the percentage for $57.3 \%$ of the variation in achieving functional efficiency in the Jordanian Customs Department (as a dependent variable), while the remaining $42.7 \%$ means that there are independents variables Not included in the study model or may revert to random error affect in achieving the functional efficiency in the Jordanian Customs Department in the sample. The results showed that there was a positive effect on the auditing of individuals in the achievement of functional efficiency, which reached (4.548) and 
INTERNATIONAL JOURNAL OF ACADEMIC RESEARCH IN BUSINESS AND SOCIAL SCIENCES

Vol. 9, No. 3, March, 2019, E-ISSN: 222 2-6990 @ 2019 HRMARS

statistically significant (0.00). There was a positive effect in auditing the policies in achieving functional efficiency, In statistical terms 5.977 and with statistically significant 0.000 .

\section{Discussions and Result}

In this study, the impact of the strategic audit of human resources on the efficiency of employees in the Jordanian Customs Department was examined. The results of the study showed that there is an impact of the strategic audit of human resources in all the aspects (personnel auditing, policy auditing) in the efficiency of employees (Process efficiency, Structural efficiency and Functional efficiency) in the Jordanian Customs Department. This indicates that the Jordanian Customs Department is practicing strategic auditing well, both at the level of individuals and at the level of policies, because of its necessary need and urgent in the department, in the national economy, and this supported by (Al-Shaabani\& Al-Jamili\& Hussein 2012) this study reaches that there is relationship between the efficiency and effectiveness of Iraqi industrial companies and the method of evaluation used, the efficiency and effeteness of industrial companies are increased by using of the strategic audit system and it is related with the effectiveness of strategic audit system in the organization is strongly related to the information system used ( Shaban 2012 ) Noted that human resources audits are used to measure and evaluate the activities of individuals in the organization, provide feedback on human resources functions to executives and human resources professionals, and help managers to achieve the human resource needs of the organization.

The result indicates that workers have all the necessary skills to perform the work entrusted to them at the best degree, they have sufficient information about their responsibilities, they have full knowledge of the techniques that used in their customs duties and that are governed by a system that determines the form and nature of the customs work by monitoring their performance permanently and continuously, There is also coordination and cooperation among individuals in all the various departments in order to raise the level of customs work. This finding coincided with the study (Hamdi, 2014), which found that the active competencies are one of the elements of excellence and career success. All the knowledge and skills gained may not be enough to reach desirable results in totality, and this is what referred to him (Wojciechpajak, 2012) where he was considered checking individuals as a tool to improve the procedures and processes related to human resources within the organization, and demonstrated the importance of a methodology for the audit work to detect the underlying basic problems of the organization.

The strategies and policies adopted by the Jordanian Customs Department contribute achieving in the efficiency of the employees (practical, functional and structural) through their application to the policies of the department when they are completed for their work, which fulfills the objectives set by the Department. This has been reflected in the work of The Jordanian Customs services that engaging indecision making process, and the establishment works group of task forces to solve the problems faced by the administration in the customs duties, and to allow the workers to learn and acquire new skills in the field of customs work, through specialized training courses and continuous, appearance of rewards and compensation system that are suitable with the efforts in the work, The results are not consistent with Momani's study (2015), which considers reviewing the employment policies of the Jordanian Ministry of Health and developing mechanisms to maintain skilled workers and attract individuals with knowledge and experience to fill vacant positions and who are in line with 
the Ministry's values and aspirations. , And the need for the Ministry to adopt the strategic audit of human resource management as an input to improve performance, increase productivity and reduce cost and thus achieve the strategic objectives planned in advance through the establishment of a new department in the ministry under the name of (strategic audit of resource management Human) and appear in the organizational structure.

\section{Implications}

This study provides a number of theoretical contributions to the literature of management strategy in the improving staff efficiency, and expands the range fields of search in strategic management by examining how strategic auditing can improve and enhance the efficiency of employees. The use of a different model in the study of the relationship between the organization's strategies, and it's impact on the efficiency of performance which have been measured through the process efficiency, functional efficiency and structural efficiency that have many contributions in strategic management. There are many previous researches which search significantly about the effect of strategic management on the performance. However, there are little of studies which search and examine how the impact of strategic auditing on organizational performance, especially the efficiency of performance. This research was carried out in an attempt to fill this gap between literature. The results and arguments that are presented in the current study encourage a better understanding how strategic auditing directly affected the different dimensions of organizational performance, especially performance efficiency.

The Customs Department is considered one of the most important government sectors in Jordan. It has a number of customs centers, which require endless accuracy by its employees. The study examined the impact of the strategic audit of human resources management in raising the efficiency of employees. The study, by selecting its dimensions and developing a model based on it, that serves the study community. A set of recommendations were presented for adoption by the Jordanian Customs Department, such as the definition of employees in strategic audit. The need to clarify the performance criteria help to stimulate the motivation of individuals and create incentive to improve their productivity, ensure that all employees in the performance evaluation process, regardless of their level of employment and employee news, are evaluated, and that human resource management is supported by sound manpower planning and scientific selection methods.

\section{References}

Abu Al-Jadeeel, H. S. (2012). Core Competencies of Human Resource Management Managers, unpublished Master's Thesis, College of Business Administration, Jeddah, Kingdom of Saudi Arabia.

Akhwirshidah, A. (2006). Accountability and Effectiveness in Educational Management / Amman, Dar Al-Hamed

Al Shakli, M.\& Kubisi, S. (2011). The Role of tacit Knowledge in Building Fundamental Capabilities, A Survey of the Views of a Sample of the Directors of the Financial Control Bureau in Iraq, Anbar University Journal of Economic and Administrative Sciences.

Al-Douri, Z. M. (2005). Strategic Management, Concepts, Processes and Case Studies, Amman, Dar Al-Yazuri. 
Al-Shaabani, S. I. \& Al-Jamili, W. H. (2012). Features of the Implementation of Strategic Auditing in Iraq: A Study of Industrial Companies in Nineveh Province, Anbar University Journal of Economic and Administrative Sciences (4), 373-396.

Anne, B. (2014). PHR/SPHR Professional in Human Resources certification study Guide4rd edition Indiana,USA ،john wiley sons.

Asia, R. (2010). Role of competencies in achieving competitive advantage, Case study of the National Institute of Civil Engineering and Construction, Master Thesis, Algeria, University of Mohamed Boufara, Boumerdes.

Aswathappa, K. (2005). Human Resource And Personnel management $4^{\text {th }}$ edition, new Delhi, Tata McGraw-Hill Education.

Ben Jeddou, M. E. (2013). Role of Competencies in Achieving the Excellence Strategy, Unpublished Master Thesis, Setif University 1, Algeria.

Berqawi, W. (2013). Human Resources Management, Concept, Functions and Strategies, Amman, Dar Yazidi.

Debrincat, G., (2014). The effectiveness of performance Appraisal systems: Employee Relations Academic Publishing.

Habib, T., \& Jilali, B. A. (2009). Development of competencies and development of human resources, i (1), Alexandria, University Culture Foundation.

Hamidi, A. H. (2014). Role of Competencies in Enhancing Competitive Strategy, Case Study of Public Institution, University of Mohamed KhaderBiskra, Algeria.

Hamley, A.B. (2011). Job Evaluation of Individuals in the Institution, Unpublished Master Thesis, University of Abu Bakr Belqayd, Algeria.

Harem, H., (2013). Human Resource Management Integrated Framework, Jordan, Dar Al-Hamed Publishing.

Imam A., Muhammad A. A. \& Ali T. M., (2013). Towards a Framework for Human Resource Audit: Applied Study, Sudan University of Science and Technology, Journal of Economic Sciences, 14 (01), 111-133.

Irtaimeh, H. J., Obeidat, A. M., Abualloush, S. H., Khaddam, A. A. (2016) Impact of Business Intelligence on Technical Creativity: A Case Study on AlHekma Pharmaceutical Company, European Scientific Journal , vol.12, No.28,PP,502-519

John, B. H. (2007). Human Resource Management :An Experiential Approach. $4^{\text {th }}$ ed .Boston:Irwin McGraw Hill .

Juma, A. H., (2009), Introduction to Auditing and Modernization, Amman, Dar Al Safa for Publishing and Distribution.

Mackey, D., (2006). Trans forming Training: A guide to creating A flexible learning environment, USA, Kogan page publishers.

Masadeh, M. A., (2013). Strategic Management, Concepts-Operations-Case Studies, Amman, Dar AlHamed Publishing.

Mirza. S. S., (2009). Human Resources Management $4^{\text {th }}$ edition, New Delhi.

Momani, H., (2015). The Impact of Strategic Audit on Human Resource Management in Achieving Strategic Goals, Unpublished Master Thesis, Jadra University, Irbid. 
Noureddine, E., (2008). Efficiency, Effectiveness, Ethics of the Foundation: The Perspective of the Beneficiaries, Unpublished PhD Thesis, University of Mohamed Khader, Algeria.

Obeidat A. M. \& Otibi, G. A., (2015). The Impact of Knowledge Sharing Tools on Levels of Organizational Learning (Field Study on Jordanian Commercial Banks) Australian Journal of Basic and Applied Sciences, 9(5), 253-267.

Obeidat, A. M., Abualoush, S. H., Irtaimeh, H. J., Khaddam, A. A.,\& Bataineh, K.. A.(2018). The role of organizational culture in enhancing the human capital applied study on the social security corporation, Int. J. Learning and Intellectual Capital, Vol. 15, No. 3, 258-276.

Pickett, K, H.Spencer,(2010). The Internal Auditing Handbook, 3ed edition, uk,john wiley \&sons.

Salem, M. S., (2009). Human Resource Management Strategic Strategic Approach (I 1), Jordan, Thira Publishing and Distribution.

Sekaran, U., (2003). Research methods for business: A skill-building approach, 5ed, new York : John Wiley and Sons Inc .

Robbins, S. P. \& Coulter, M. (2012). Management, $11^{\text {th }}$ ed, Prentice Hall. 